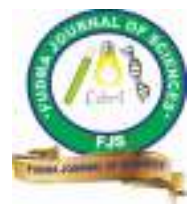

FUDMA Journal of Sciences (FJS)

ISSN online: $2616-1370$

ISSN print: 2645 - 2944

Vol. 4 No. 3, September, 2020, pp $114-120$

DOI: https://doi.org/10.33003/fjs-2020-0403-276

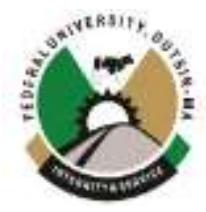

\title{
IMPROVING THE LOCAL GEOMETRIC GEOID MODEL OF FCT ABUJA ACCURACY BY FITTING A HIGHER ORDER/DEGREE POLYNOMIAL SURFACE
}

\author{
${ }^{* 1}$ Oluyori, P. D. and ${ }^{2}$ Eteje, S. O. \\ ${ }^{1}$ P. D. Horvent Surveys Ltd, Abuja Nigeria \\ ${ }^{2}$ Eteje Surveys and Associates, Benin City, Edo State, Nigeria \\ ${ }^{*}$ Corresponding Author’s Email: dareoluyori@gmail.com
}

\begin{abstract}
The improvement of the accuracy of a local geometric geoid model using the same data set (geoid heights) requires the fitting of a higher degree polynomial surface to the data set. Consequently, this paper presents improving the local geometric geoid model of FCT, Abuja accuracy by fitting a higher order polynomial surface. A fifth degree polynomial surface was fit to the existing geoid heights of 24 points used previously for the determination of the geometric geoid model of the study area to improve its accuracy. The least squares adjustment technique was applied to compute the model parameters, as well as the fit. The RMSE index was applied to compute the accuracy of the model. The computed accuracy $(0.081 \mathrm{~m})$ of the model was compared with those of the previously determined geoid models (Multiquadratic, $0.110 \mathrm{~m}$ and Bicubic, $0.136 \mathrm{~m}$ models) of the study area to determine which of the models best fit the study area, as well as has the highest resolution. The comparison result shows that the fifth degree polynomial surface best fit the study area.
\end{abstract}

Keywords: Accuracy, Higher Degree, Polynomial, Geometric Geoid, model.

\section{INTRODUCTION}

The GNSS observation that uses the Global Positioning System (GPS)/Global Navigation Satellite System receivers gives the coordinates and elevations of stations at various points of measurements. The system elevations are relative to the ellipsoid. In other words, they are not to the Mean Sea Level (MSL), as well as the geoid. Therefore, they are not practical heights and not used for engineering construction purposes. The orthometric heights of points are obtained relative to benchmarks with spirit levelling whose procedure is tedious and time-consuming. Most times, the locations of benchmarks are far from project areas. Sometimes the closest ones are at $3 \mathrm{~km}$ to $5 \mathrm{~km}$ from project areas. To carry out spirit levelling for such distances to determine the orthometric height of temporal benchmarks (TBM) of project areas is not always easy. If all the turning points of a project area, are surveyed with the GNSS observation, then the positions and ellipsoidal heights of the observed points can be obtained. Since the ellipsoidal heights $(h)$ are not useful for engineering purposes, there is a need to be converted to orthometric heights $(\mathrm{H})$. The conversion of the ellipsoidal heights (h) to orthometric heights $(\mathrm{H})$ requires geoid heights $(\mathrm{N})$, as well as a local geoid model of the area. If the geoid heights $(\mathrm{N})$ of points are known, then their orthometric heights are computed using the relation (Oluyori et al., 2018),

$\mathrm{H}=\mathrm{h}-\mathrm{N}$

The Geoid is one of the Earth's shapes. Geoid surface is used to approximate the physical shape of the Earth. It is the equipotential surface of the Earth's gravity field which more or less coincides with the mean sea level (Borge, 2013). Ubajekwe (2011) also defined the geoid as the equipotential surface of the earth's attraction and rotation which coincides on average with the mean sea level in the open Ocean. It is the surface which coincides with the mean sea level assuming that the sea was free to flow under the land in small frictionless channels. Moritz and Hofmann (2005) stated that the geoid coincides with that surface to which the oceans would conform over the entire earth if free to adjust to the combined effect of the earth mass attraction (gravitation) and the centrifugal force of the earth's rotation. They also explained that the geoid is a surface along which the gravity potential is everywhere equal and to which the direction of gravity is always perpendicular when optical instruments containing gravity reference levelling devices are properly adjusted during observation coincides with the direction of gravity and are therefore perpendicular to the geoid. Civil engineers use the geoid as the reference surface for elevations while oceanographers use it for studies of ocean circulation, currents and tides. It is also valuable to geophysicists for displacement studies, geophysical interpretation of the Earth's crust, and prospecting (Borge, 2013).

The absence of the Nigeria local geoid model has resulted in the determination of the geoid models of local areas in the country. The determined geoid models have different accuracy. Most of them were determined using the geometric and the gravimetric methods while some others were the gravimetricgeometric method. The Local geoid model of the Federal Capital Territory (FCT), Abuja has been determined using the GPS/Levelling, as well as the geometric method. The comparison of two geometric geoid surfaces (Multiquadratic and Bicubic geoid surfaces), realized the local geoid model of the study area. The two surfaces were respectively 9 (fourth degree polynomial) and 10 (third degree polynomial) parameters. The accuracy obtained for the two geometric geoid models are respectively $0.110 \mathrm{~m}$ and $0.136 \mathrm{~m}$ and were recommended for application in the study area with more confidence in Multiquadratic geoid model as its accuracy was better than that of the Bicubic geoid surface. The obtained accuracy were a bit low. It was as a result of the number of 
points used in the study. Although the quadratic-based programs according to Schmidt et al. (2003) gives a more stable result, the high-order local surfaces can fit more complex landform features and reliable only for very accurate data from GNSS/GPS space methods. The accuracy of the local geometric geoid model increases as the number of observations, as well as points used in the study, approximates that of the model parameters/terms (Eteje et al., 2019). According to Eteje et al., (2019), the accuracy of the local geometric geoid model is highest at a unique solution that is, when the number of the observation is equal that of the model parameters, as well as terms. Here, the consideration is that the number of model terms increases as the degree increases. Considering Schmidt et al. (2003) and Eteje et al. (2019), the improvement of the local geometric geoid model of the Federal Capital Territory (FCT), Abuja requires a higher degree polynomial geoid surface whose number of model terms, as well as parameters approximates the number of observations/points used in the study. As a result, this study presents improving the local geometric geoid model of FCT, Abuja accuracy by fitting a higher order polynomial surface.

To realize this, a higher order (Quintic) polynomial geoid surface with 21 parameters and degree 5 is fit to the geoid heights of 24 points in the study area. These were the points and geoid heights used in the previous study. The fitting of the Quintic polynomial geoid surface to the geoid heights of the points requires the computation of the model parameters with the geoid heights and coordinates of the points using the least squares adjustment technique. The application of the coordinates of the points in the model parameters computation involves the computation of the study area centroid coordinates and finding the differences between the centroid coordinates and the coordinates of the points. Subsequently, the geoid heights and the differences between the centroid coordinates and the positions of the points are used for the computation of the model parameters. The accuracy of the model is computed using the Root Mean Square Error (RMSE) Index.

\section{The Study Area}

The Federal Republic of Nigeria consists of 36 states and Federal Capital, the FCT, Abuja. Nigeria is located between $4^{\circ}$ and $14^{\circ}$ latitude and $2^{\circ}$ and $15^{\circ}$ longitude occupying an area of $923768 \mathrm{~km}^{2}$. The two major rivers in the country are Niger and Benue that meet at Lokoja. The FCT lies between $8^{\circ} 15^{\prime} \mathrm{N}$ to $9^{\circ} 12^{\prime} \mathrm{N}$ and $6^{\circ} 27^{\prime} \mathrm{E}$ to $7^{\circ} 23^{\prime} \mathrm{E}$. Figures 1 and 2 are maps of Nigeria and Federal Capital Territory Area Councils respectively.

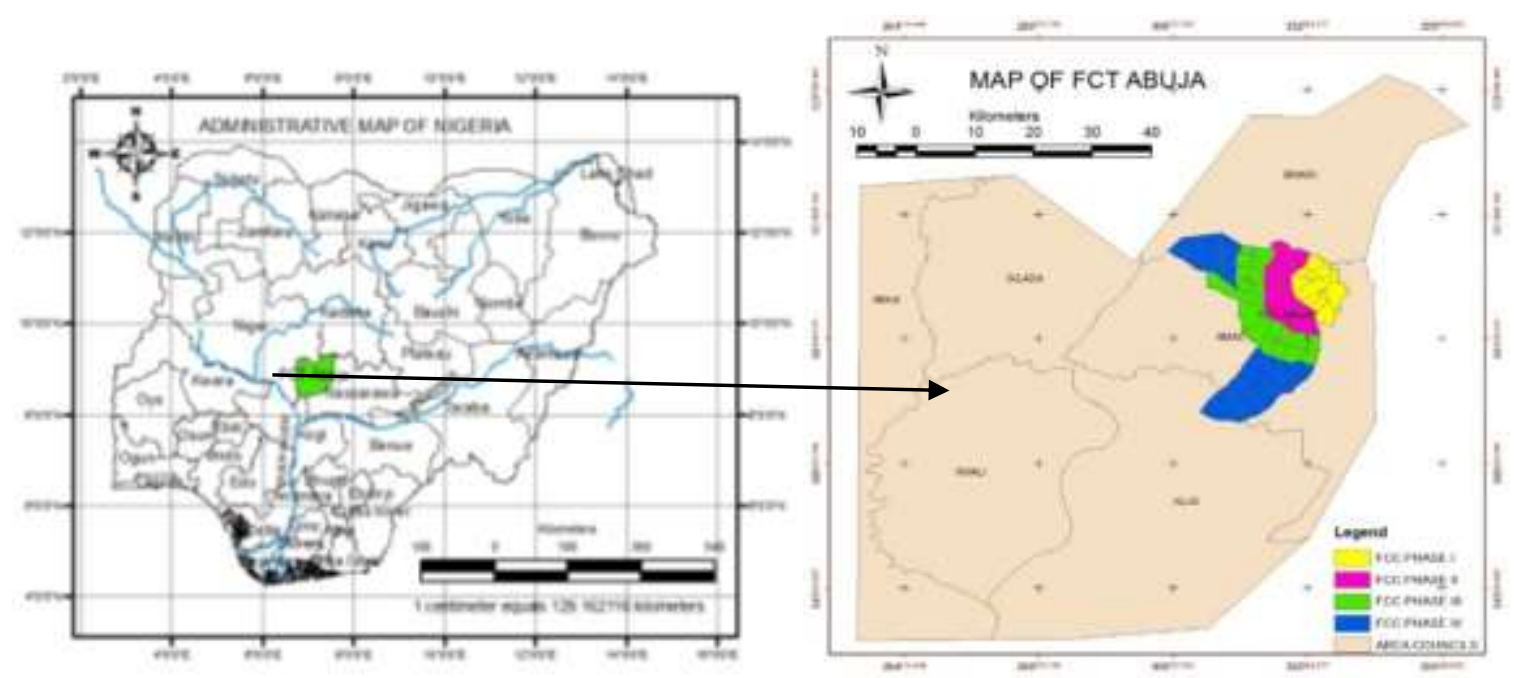

Figure1: Nigeria map with thirty-six states and FCT. Fig. 2: Map of FCT Area Councils Source: Oluyori et al. (2018)

\section{Polynomial Models}

Polynomial geoid models, as well as surfaces, are fitted to the known geoid heights of points to enable the geoid heights of new points, be computed by interpolation using the coordinates of the points (Eteje et al., 2019). The Multiquadratic and Bicubic models had earlier been applied in the Federal Capital Territory, Abuja to determine its local geometric geoid model (Oluyori, 2019). In the attempts to improve the accuracy of the determined geoid model, having considered Schmidt et al. (2003) and Eteje et al. (2019), there is a need to apply a fifth-degree (Quintic) polynomial surface in the study area. The Multiquadratic and the Bicubic models as given by Oluyori (2019) and the fifth degree polynomial surface given by Awange et al. (2010) and Eteje et al. (2019) are respectively

$$
\begin{aligned}
& N=a_{0}+a_{1} x+a_{2} y+a_{3} x^{2}+a_{4} y^{2}+a_{5} x y+a_{6} x^{2} y+a_{7} x y^{2}+a_{8} x^{2} y^{2} \\
& N=a_{0}+a_{1} x+a_{2} y+a_{3} x^{2}+a_{4} x y+a_{5} y^{2}+a_{6} x^{3}+a_{7} x^{2} y+a_{8} x y^{2}+a_{9} y^{3}
\end{aligned}
$$




$$
\begin{aligned}
N= & a_{0}+a_{1} x+a_{2} y+a_{3} x^{2}+a_{4} x y+a_{5} y^{2}+a_{6} x^{3}+a_{7} x^{2} y+a_{8} x y^{2}+a_{9} y^{3}+ \\
& +a_{10} x^{4}+a_{11} y^{4}+a_{12} x^{3} y+a_{13} x^{2} y^{2}+a_{14} x y^{3}+a_{15} x^{5}+a_{16} y^{5}+a_{17} x^{4} y+ \\
& +a_{18} x^{3} y^{2}+a_{19} x^{2} y^{3}+a_{20} x y^{4}
\end{aligned}
$$

Where,

$$
\begin{aligned}
& \mathrm{N}=\text { Geoid height of point } \\
& y=A B S\left(Y-y_{o}\right) \\
& x=A B S\left(X-x_{o}\right) \\
& Y=\text { Northing coordinate of observed station } \\
& X=\text { Easting coordinate of observed station } \\
& y_{o}=\text { Northing coordinate of the origin (average of the northing coordinates) } \\
& x_{o}=\text { Easting coordinate of the origin (average of the easting coordinates) } \\
& a_{o}, a_{1}, a_{2}, \ldots, a_{n} \text { are the unknown model parameters. }
\end{aligned}
$$

\section{Least Squares Adjustment Technique}

The fitting of a polynomial surface to a set of geoid heights requires the computation of the polynomial, as well as the geometric geoid model parameters using the least squares technique. The least squares models for the computation of the geometric geoid model parameters are detailed in Eteje and Oduyebo (2018).

\section{Root Mean Square Error (RMSE) Computation}

The Root Mean Square Error (RMSE) is an indicator of accuracy. It is used for the computation of the accuracy of local geometric geoid models. Its application for accuracy computation in geoid modelling involves the comparison of the computed geoid heights obtained from the differences between the ellipsoidal and the orthometric heights and the model geoid heights of points. The RMSE index used for accuracy computation as given by Eteje and Oduyebo (2018) is

$$
R M S E= \pm \sqrt{\frac{V^{T} V}{n}}
$$

Where,

$$
\begin{aligned}
& V=(N)_{K N O W N}-(N)_{M O D E L} \\
& (N)_{K N O W N}=\text { Point known geoid height } \\
& (N)_{M O D E L}=\text { Point model geoid height } \\
& n=\text { Number of points }
\end{aligned}
$$

\section{METHODOLOGY}

\section{Data Acquisition}

The data used in this study included the existing UTM zone 32 coordinates, existing orthometric heights and GNSS observation ellipsoidal heights of 24 control stations within the Federal Capital Territory (FCT), Abuja. The existing coordinates and orthometric heights of the points were obtained from the Surveying and Mapping Department of the Federal
Capital Development Authority (FCDA), Abuja while their respective ellipsoidal heights were obtained from GNSS observation of the existing controls. These were the data used previously for the determination of the local geometric geoid model of FCT, Abuja and are detailed in Oluyori (2019) and Oluyori et al. (2019). Figure 2 shows the GNSS observation of the points while Table 1 shows the coordinates, orthometric heights and the ellipsoidal heights of the points. 


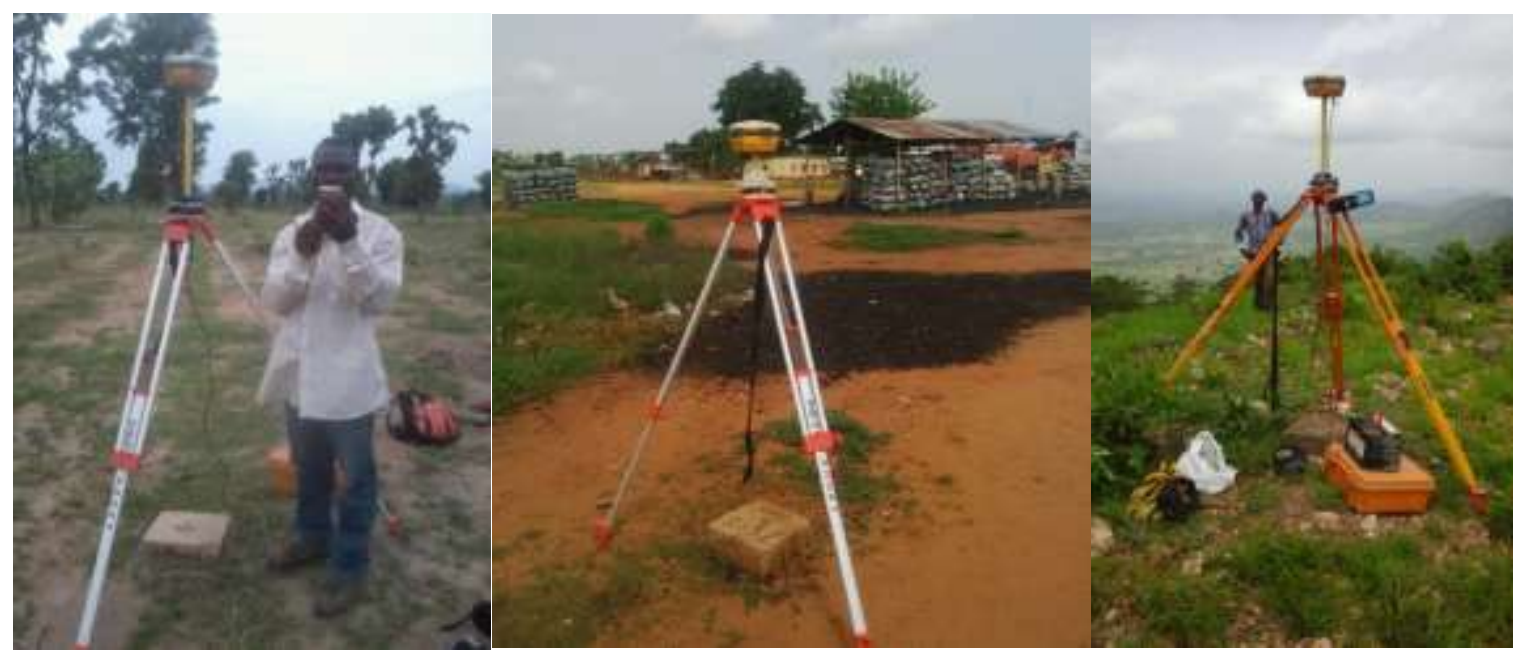

FCT 260P Base Station $\quad$ FCT 2652S (Rover Station)

FCT130P Base Station

Figure 2: GNSS Observation of the Control Stations

Table 1: Control Stations Coordinates, Orthometric Heights and Ellipsoidal Heights

\begin{tabular}{|c|c|c|c|c|}
\hline \multirow{2}{*}{$\begin{array}{l}\text { CONTROL } \\
\text { POINTS }\end{array}$} & \multicolumn{3}{|c|}{ COORDINATE REGISTER VALUE } & \multirow{2}{*}{$\begin{array}{c}\text { GNSS } \\
\text { ELLIPSOIDAL } \\
\text { HEIGHT (m) }\end{array}$} \\
\hline & $\begin{array}{c}\text { EASTINGS (m) } \\
\text { (e)X }\end{array}$ & $\begin{array}{l}\text { NORTHINGS } \\
\text { (m) (n)Y }\end{array}$ & $\begin{array}{c}\text { EXISTING ORTHO. } \\
\text { HEIGHTS, H (m) }\end{array}$ & \\
\hline FCC11S & 331888.114 & 998442.043 & 485.447 & 509.396 \\
\hline FCT260P & 255881.175 & 993666.807 & 201.944 & 224.740 \\
\hline FCT103P & 340639.766 & 998375.578 & 532.558 & 556.836 \\
\hline FCT12P & 333743.992 & 1008308.730 & 735.707 & 760.192 \\
\hline FCT19P & 337452.408 & 996344.691 & 635.644 & 659.824 \\
\hline FCT2168S & 310554.927 & 1009739.930 & 431.087 & 455.274 \\
\hline FCT24P & 322719.776 & 1001884.850 & 453.804 & 477.987 \\
\hline FCT276P & 351983.716 & 1025998.314 & 625.572 & 649.848 \\
\hline FCT4154S & 329953.882 & 1003831.280 & 476.981 & 501.232 \\
\hline FCT4159S & 326124.422 & 1003742.860 & 452.230 & 476.553 \\
\hline FCT66P & 299148.035 & 998114.283 & 297.111 & 321.115 \\
\hline FCT9P & 329821.512 & 1007612.091 & 497.253 & 521.693 \\
\hline FCT35P & 322183.380 & 992926.363 & 427.171 & 451.299 \\
\hline FCT57P & 303234.270 & 992916.402 & 323.844 & 347.795 \\
\hline FCT4028S & 330164.634 & 1001388.240 & 449.592 & 473.942 \\
\hline FCT53P & 308943.361 & 993406.773 & 351.943 & 375.955 \\
\hline FCT4652S & 329441.767 & 997474.808 & 462.711 & 487.113 \\
\hline FCT162P & 270791.291 & 934625.533 & 189.696 & 215.091 \\
\hline FCT130P & 330982.584 & 952889.869 & 695.608 & 719.383 \\
\hline FCT2327S & 282526.612 & 973821.470 & 183.287 & 207.482 \\
\hline FCT2652S & 271370.273 & 945385.429 & 138.952 & 163.741 \\
\hline FCT2656S & 272644.591 & 941062.460 & 204.724 & 229.229 \\
\hline FCT83P & 332954.205 & 987231.606 & 568.752 & 592.819 \\
\hline XP382 & 284074.729 & 983364.863 & 274.586 & 298.390 \\
\hline
\end{tabular}




\section{Data Processing}

The positions and orthometric heights of the points were obtained from the Surveying and Mapping Department of the FCDA while the ellipsoidal heights were obtained from the GNSS processing results. The geoid heights of the points were computed by finding the differences between the GNSS ellipsoidal heights and the orthometric heights, as well as using equation (1). Table 2 shows the computed geoid heights of the points.

Table 2: Computed Geoid Heights of Stations

\begin{tabular}{|c|c|c|c|}
\hline STATION & EASTINGS (m) (e)X & NORTHINGS (m) (n)Y & GEOID HEIGHT (m) \\
\hline FCC11S & 331888.114 & 998442.043 & 23.949 \\
\hline FCT260P & 255881.175 & 993666.807 & 22.787 \\
\hline FCT103P & 340639.766 & 998375.578 & 24.278 \\
\hline FCT12P & 333743.992 & 1008308.730 & 24.485 \\
\hline FCT19P & 337452.408 & 996344.691 & 24.180 \\
\hline FCT2168S & 310554.927 & 1009739.930 & 24.187 \\
\hline FCT24P & 322719.776 & 1001884.850 & 24.183 \\
\hline FCT276P & 351983.716 & 1025998.314 & 24.276 \\
\hline FCT4154S & 329953.882 & 1003831.280 & 24.251 \\
\hline FCT4159S & 326124.422 & 1003742.860 & 24.323 \\
\hline FCT66P & 299148.035 & 998114.283 & 24.004 \\
\hline FCT9P & 329821.512 & 1007612.091 & 24.440 \\
\hline FCT35P & 322183.380 & 992926.363 & 24.128 \\
\hline FCT57P & 303234.270 & 992916.402 & 23.951 \\
\hline FCT4028S & 330164.634 & 1001388.240 & 24.350 \\
\hline FCT53P & 308943.361 & 993406.773 & 24.012 \\
\hline FCT4652S & 329441.767 & 997474.808 & 24.402 \\
\hline FCT162P & 270791.291 & 934625.533 & 25.395 \\
\hline FCT130P & 330982.584 & 952889.869 & 23.775 \\
\hline FCT2327S & 282526.612 & 973821.470 & 24.195 \\
\hline FCT2652S & 271370.273 & 945385.429 & 24.789 \\
\hline FCT2656S & 272644.591 & 941062.460 & 24.505 \\
\hline FCT83P & 332954.205 & 987231.606 & 24.067 \\
\hline XP382 & 284074.729 & 983364.863 & 23.804 \\
\hline
\end{tabular}

The computations of the model parameters and the accuracy of the Multiquadratic model, equation (2) and the Bicubic model, equation (3) were carried out with Microsoft Excel programs and are detailed in previous studies (Oluyori, 2019 and Oluyori et al., 2019) that determined the local geometric geoid model of the study area. The model parameters of the fifth degree polynomial surface (equation (4)) were computed with the geoid heights of the points and the absolute differences between the control stations coordinates and the centroid point coordinates using the least squares technique. The accuracy of the higher degree polynomial model was computed using equation (5). The procedures for the computation of equation (4) parameters (the fit) and its accuracy are detailed in Eteje and Oduyebo (2018). The computations were also carried out with a Microsoft Excel program developed in this study for the application of the geometric geoid model in the study area.

\section{RESULTS AND DISCUSSION}

Figure 3 presents the plot of the existing/computed, Multiquadratic, Bicubic and the Quintic, as well as the fifth degree polynomial surface geoid heights. It was done to present graphically, the shapes of the plotted surfaces and determine which of the three surfaces best fit the computed geoid heights of the points, as well as has the highest resolution. In Figure 3, the green, red, orange and the blue lines respectively represent the shapes of the existing/computed, Multiquadratic, Bicubic and the Quintic geoid heights. It can be seen in Figure 3 that the blue line fits the green line most. This implies that the Quintic (fifth degree) polynomial surface has the highest resolution. It also confirms Schmidt et al. (2003) and Eteje et al. (2019) statements and conclusions. 


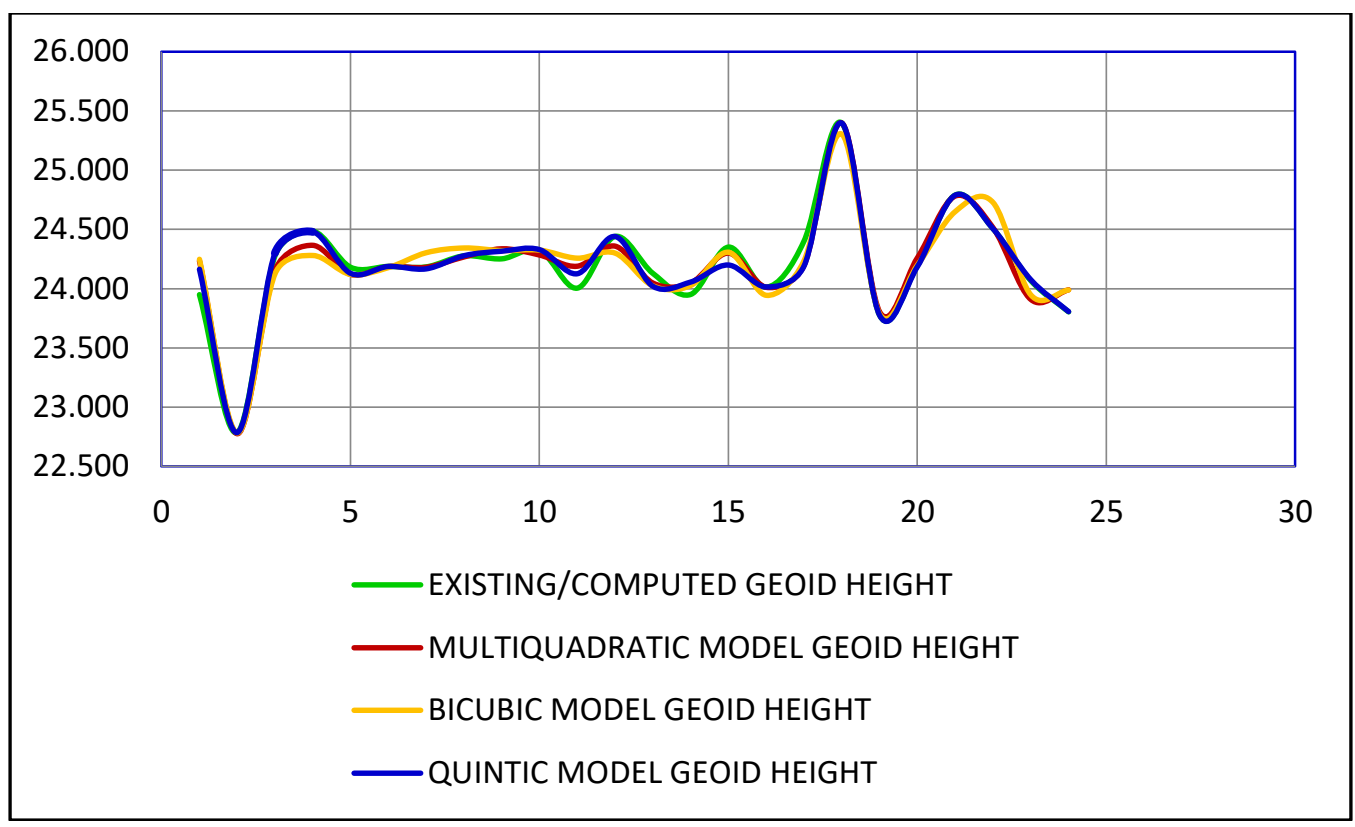

Figure 3: Plot of the Computed and the Three Models' Geoid Heights

Figure 4 presents the plot of the RMSE of the Multiquadratic, Bicubic and the Quintic, as well as the fifth degree polynomial surfaces. It was done to present the accuracy of the three surfaces and determine which of them has the highest accuracy, as well as resolution. The accuracy of the model varies inversely to the values of the computed RMSE, as well as the heights of the histogram bars. It can be seen in Figure 4 that the RMSEs of the Multiquadratic, Bicubic and the Quintic surfaces are respectively $0.110 \mathrm{~m}, 0.136 \mathrm{~m}$ and $0.081 \mathrm{~m}$ which implies that the Quintic model has the highest accuracy, as well as resolution. It also confirms the improvement of the accuracy of the local geometric geoid model of the study area and agrees with Schmidt et al. (2003) and Eteje et al. (2019). The accuracy of the Multiquadratic model ( 9 parameters) that is higher than that of the Bicubic model (10 parameters) is as a result of its degree. It is a fourth-degree polynomial. Therefore, the accuracy of the models' increases in this order, Bicubic (third degree), Multiquadratic (fourth degree) and Quintic (fifth degree) surfaces. This also agrees with Eteje et al. (2019).

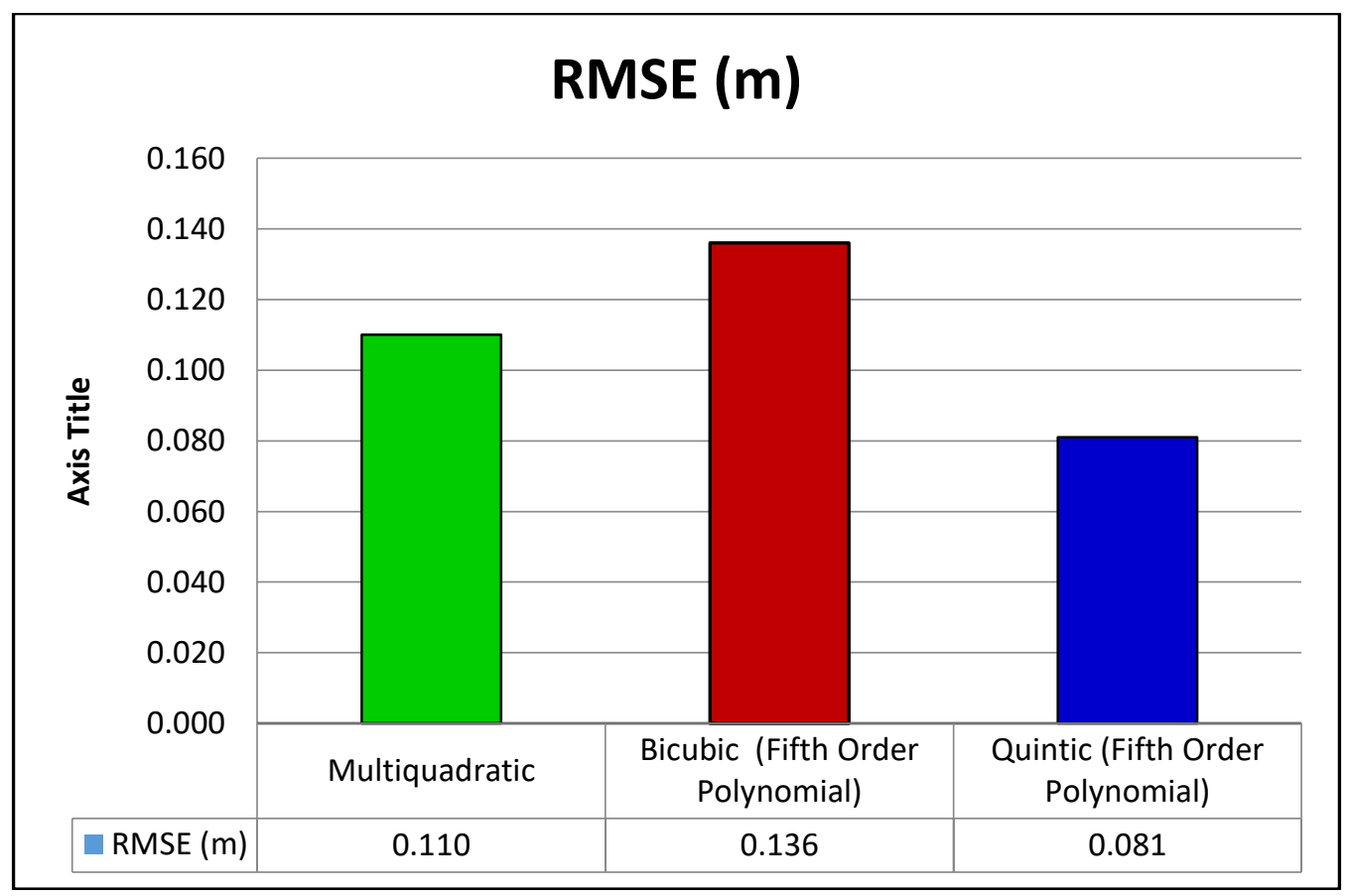

Figure 4: Plot of the Three Models' RMSE/Accuracy 


\section{CONCLUSION AND RECOMMENDATION}

The study has improved the accuracy of the local geometric geoid model of the Federal Capital Territory (FCT), Abuja by fitting a higher degree (Quintic) polynomial surface to the existing geoid heights of the study area, computing the accuracy of the model and compared the computed accuracy with those of the existing geometric geoid models of the study area. The study shows that the Quintic polynomial geoid model has the highest accuracy, as well as resolution. Hence, improved the accuracy of the local geometric geoid model of the study area. The study has also confirmed the statement by Eteje et al., (2019) that the accuracy of the local geometric geoid model increases as the degree of the model increases. It has as well developed a Microsoft Excel program for the application of the Quintic polynomial geoid model in the study area. The study recommends that whenever a highly reliable data set (geoid heights) is required in the study area, the Quintic polynomial geoid model, as well as program, should be applied.

\section{REFERENCES}

Awange, J. I., Grafarend, E. W., Palanez, B. and Zaletnyik, P. (2010). Algebraic Geodesy and Geoinformatics. Springer and Business Media, 2010.

Borge, A. (2013). Geoid Determination over Norway Using Global Earth Gravity Models. Published MSc Thesis, Department of Civil and Transport Engineering, Norwegian University of Science and Technology.

Eteje, S. O. and Oduyebo, O. F. (2018). Local Geometric Geoid Models Parameters and Accuracy Determination Using Least Squares Technique. International Journal of Innovative Research and Development, 7(7), 251-257. DOI:
http://doi.org/10.24940/ijird/2018/v7/i7/JUL18098.

Eteje, S. O., Oduyebo, O. F. and Oluyori, P. D. (2019). Relationship between Polynomial Geometric Surfaces Terms and Observation Points Numbers and Effect in the Accuracy of Geometric Geoid Models. International Journal of Environment, Agriculture and Biotechnology (IJEAB), 4(4), 1181-1194. DOI: https://dx.doi.org/10.22161/ijeab.4444.

Moritz, H. and Hofmann-Wellenhof, B. (2005). Physical Geodesy. Springer Vienna.

Oluyori, P. D. (2019). Modelling of Orthometric Heights from Multi-Networks of GNSS/Precise Levelling in FCT, Abuja. Unpublished Ph.D Dissertation, Department of Surveying and Geoinformation, Nnamdi Azikiwe University Awka, Anambra State, Nigeria.

Oluyori, P. D., Ono, M. N. and Eteje, S. O. (2018). Computations of Geoid Undulation from Comparison of GNSS/Levelling with EGM 2008 for Geodetic Applications. International Journal of Scientific and Research Publications, 8(10), 235-241. DOI: http://dx.doi.org/10.29322/IJSRP.8.10.2018.p8230.

Schmidt, J., Evans, I. S. and Brinkmann, J. (2003).Comparison of Polynomial Models for Land Surface Curvature Calculation. International Journal of Geographical Information Science, 17(8), 797-814. DOI: https://dx.doi.org/10.1080/13658810310001596058.

Ubajekwe, R. (2011). Geometric Geodesy. Unpublished Lecture Note, Department of Surveying and Geoinformation, Nnamdi Azikiwe University Awka, Anambra State, Nigeria. 